\title{
Chitosan Coated Microparticles Enhance Simvastatin Colon Targeting and Pro-Apoptotic Activity
}

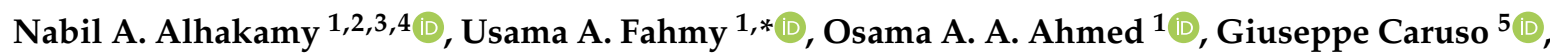
Filippo Caraci ${ }^{5,6}$, Hani Z. Asfour ${ }^{7}$, Muhammed A. Bakhrebah ${ }^{8}$, Mohammad N. Alomary ${ }^{8}$, Wesam H. Abdulaal ${ }^{9}{ }^{10}$, Solomon Z. Okbazghi ${ }^{10}$, Ashraf B. Abdel-Naim ${ }^{11}$, Basma G. Eid ${ }^{11}$, Hibah M. Aldawsari ${ }^{1}$, Mallesh Kurakula ${ }^{12}$ and Amir I. Mohamed ${ }^{13}$

1 Department of Pharmaceutics, Faculty of Pharmacy, King Abdulaziz University, Jeddah 21589, Saudi Arabia; nalhakamy@kau.edu.sa (N.A.A.); oaahmed@kau.edu.sa (O.A.A.A.); aldosarih@gmail.com (H.M.A.)

2 Center of Excellence for Drug Research and Pharmaceutical Industries, King Abdulaziz University, Jeddah 21589, Saudi Arabia

3 King Fahd Medical Research Center, King Abdulaziz University, Jeddah 21589, Saudi Arabia

4 Advanced Drug Delivery Research Group, Faculty of Pharmacy, King Abdulaziz University, Jeddah 21589, Saudi Arabia

5 Oasi Research Institute-IRCCS, Via Conte Ruggero, 73, 94018 Troina (EN), Italy; forgiuseppecaruso@gmail.com (G.C.); fcaraci@unict.it (F.C.)

6 Department of Drug Sciences, University of Catania, 95125 Catania, Italy

7 Department of Medical Microbiology and Parasitology, Faculty of Medicine, Princess Al-Jawhara Center of Excellence in Research of Hereditary Disorders, King Abdulaziz University, Jeddah 21589, Saudi Arabia; hasfour@kau.edu.sa

8 Life Science and Environment Research Institute, King Abdulaziz City for Science and Technology (KACST), P.O. Box 6086, Riyadh 11442, Saudi Arabia; mbakhrbh@kacst.edu.sa (M.A.B.); malomary@kacst.edu.sa (M.N.A.)

9 Department of Biochemistry, Cancer Metabolism and Epigenetic Unit, Faculty of Science, King Abdulaziz University, Jeddah 21589, Saudi Arabia; whabdulaal@kau.edu.sa

10 Global Analytical and Pharmaceutical Development, Alexion Pharmaceuticals, New Haven, CT 06510, USA; solomon.z.okbazghi@gmail.com

11 Department of Pharmacology and Toxicology, Faculty of Pharmacy, King Abdulaziz University, Jeddah 21589, Saudi Arabia; aaabdulalrahman1@kau.edu.sa (A.B.A.-N.); beid@kau.edu.sa (B.G.E.)

12 Department of Biomedical Engineering, University of Memphis, Memphis, TN 38152, USA; mkrakula@memphis.edu

13 Department of Pharmaceutics and Industrial Pharmacy, Military Medical Academy, Cairo 11435, Egypt; miroami@gmail.com

* Correspondence: uahmedkauedu.sa@kau.edu.sa; Tel.: +966-543627789

Received: 21 March 2020; Accepted: 21 April 2020; Published: 24 April 2020

Abstract: This work aimed at improving the targeting and cytotoxicity of simvastatin (SMV) against colon cancer cells. SMV was encapsulated in chitosan polymers, followed by eudragit S100 microparticles. The release of SMV double coated microparticles was dependent on time and $\mathrm{pH}$. At pH 7.4 maximum release was observed for $6 \mathrm{~h}$. The efficiency of the double coat to target colonic tissues was confirmed using real-time X-ray radiography of iohexol dye. Entrapment efficiency and particle size were used in the characterization of the formula. Cytotoxicity of SMV microparticles against HCT-116 colon cancer cells was significantly improved as compared to raw SMV. Cell cycle analysis by flow cytomeric technique indicated enhanced accumulation of colon cancer cells in the G2/M phase. Additionally, a significantly higher cell fraction was observed in the pre-G phase, which highlighted enhancement of the proapoptotic activity of SMV prepared in the double coat formula. Assessment of annexin V staining was used for confirmation. Cell fraction in early, late and total cell death were significantly elevated. This was accompanied by a significant elevation of cellular caspase 3 activity. In conclusion, SMV-loaded chitosan coated with eudragit S100 formula exhibited 
improved colon targeting and enhanced cytotoxicity and proapoptotic activity against HCT-116 colon cancer cells.

Keywords: chitosan; simvastatin; drug release; microparticles; mucoadhesion

\section{Introduction}

According to the World Health Organization (WHO), cancer caused around 9.6 million deaths in 2018 and is a leading cause of global fatality [1]. Notably, colorectal cancer occupies second place in the most common causes of cancer death (862000 deaths), and accounts for over $9 \%$ of all cancer incidence. Unfortunately, to date, surgical resection represents the most common treatment for colorectal cancer and is often also accompanied by the removal of part of the healthy colon or rectum and nearby lymph nodes [2]. In addition to that, the recent drug formulations proposed for the cure of this specific kind of cancer have displayed several side effects [3]. For this reason, the introduction of drug delivery systems which can increase the concentrations of a selected drug at the vicinity of target cancer cells is urgently needed. Chitosan (CHIT) is a natural alkaline polysaccharide derived from chitin, characterized by its non-toxic, biocompatible, hypoallergenic, antibacterial, and biodegradable properties. Most of the properties that render chitosan a desirable carrier for the preparation of drug-loaded NPs are attributable to the primary amine group, which, among many features, is also responsible for chitosan's cationic nature, controlled drug release, and adhesion to mucosal surfaces [4,5]. As recently highlighted, chitosan-based microparticles (MPs) formulations can release several anti-tumor agents that increase drug internalization into targeted cells and enhance therapeutic effects paralleled by reduced adverse effects [6-8]. The term "Eudragit" covers a wide range of non-biodegradable, non-absorbable, and non-toxic polymethacrylate-based copolymers, including neutral as well as charged (anionic and cationic) copolymers prepared by the polymerization of acrylic and methacrylic acids or their esters. Different $\mathrm{pH}$-dependent targeted formulations can be prepared in order to obtain a selective dissolution. For example, at $\mathrm{pH}$ higher than 6 Eudragit L100 dissolves, rendering it suitable for enteric coating, while at $\mathrm{pH}$ above 7 Eudragit S100 (ES100) is soluble above pH 7 and may be used to target the colon.

Preclinical trials suggest that statins, hydroxymethylglutaryl-CoA reductase inhibitors, possess pleiotropic anticancer properties in many tumors, such as colorectal cancer, by reducing tumor cell growth and survival $[9,10]$. In particular, as it has been shown by Cho et al., simvastatin (SMV), one of the most representative members of statins, induced apoptosis in a time and dose-dependent manner in the human colorectal HCT-116 and COLO 205 cell lines. It also caused downregulation of the expression of anti-apoptotic proteins [11]. Additionally, in a mouse model of colon cancer associated with colitis, SMV resulted in a significant reduction of tumor development [11]. The novelty of this work is using chitosan from shrimp shells for targeting and controlling SMV release in order to improve its cytotoxic activity and reduce its dose and side effects.

In the present study, the influence of well-characterized SMV-loaded chitosan microparticles coated with Eudragit S100 (SMV-CHIT-ES100 MPs), as well as of its constituents, on HCT-116 cells cytotoxicity was first investigated. In order to shed more light on the potential role of SMV-CHIT-ES100 MPs in the observed decrease in cell viability in these cells, we determined its influence on cell cycle progression, apoptosis (\%), and Caspase 3 cellular content. Human colorectal carcinoma cell line (HCT-116) was selected because it represents a preferred model to study the anti-tumor potential of the prepared formula in colon cancer. Lastly, the in vivo colon targeting ability of SMV-CHIT-ES100 MPs was investigated. 


\section{Results}

\subsection{Preparation and Characterization of the SMV-CHIT-ES100 MPS}

SMV was formulated in chitosan MPs in the present study. Prepared MPs were then coated with ES100 to form MPs for colon targeting. SEM images (Figure 1) showed microparticles with an average particle size $(172 \pm 28 \mu \mathrm{m})$, with a smooth surface that showed the entrapment of SMV-Chitosan MPs in the ES100 matrix (Figure 1A-C).

A

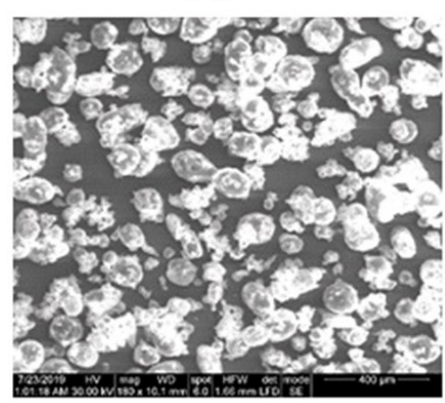

B

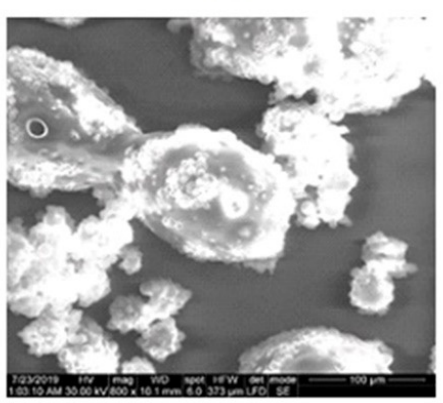

C

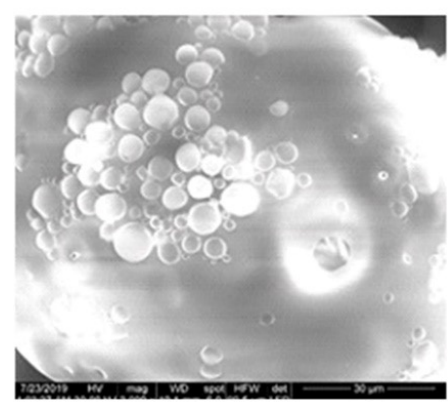

Figure 1. SEM images of characterized simvastatin (SMV)-loaded chitosan microparticles coated with Eudragit S100 (SMV-CHIT-ES MPs) at various magnification powers: $180 \times(\mathbf{A}) 800 \times($ B) and $3000 \times(C)$ showing SMV-CH MCPs entrapped within a CHIT-ES100 coat.

SMV-CHIT-ES100 MPs showed EE\% of $89.3 \pm 4.7$. Diffusion assessment aided in further characterization of the formula. Percentage of SMV released from the MPs formula at different $\mathrm{pH}$ values $(1.2,4.5$ and 7.4) compared with the raw SMV is given in Figure 2. SMV diffused in a $\mathrm{pH}$-dependent manner. SMV released from MPs not exceeded 10\% until $4 \mathrm{~h}$ (pH values 1.2 and 4.5 ). After $4 \mathrm{~h}$ at $\mathrm{pH} 7.4$, SMV release increased dramatically to reach $100 \%$ within $24 \mathrm{~h}$.

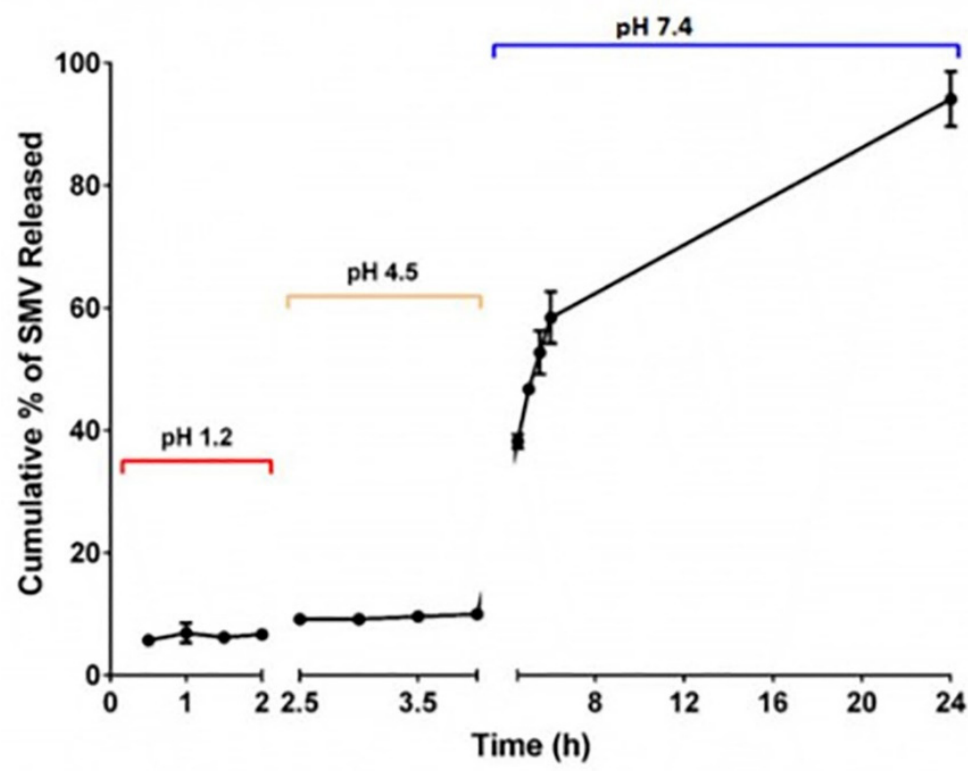

Figure 2. SMV release from SMV-CHIT-ES100 MPs at $\mathrm{pH} 1.2$ for $2 \mathrm{~h}, \mathrm{pH} 4.5$ from 2 to $4 \mathrm{~h}$, and $\mathrm{pH} 7.4$ from 4 to $24 \mathrm{~h}$. 


\subsection{In Vitro Antiproliferative Activity}

The data in Figure 3 indicate that raw SMV exhibited an obviously potent antiproliferative activity against the HCT-116 cells. Plain MPs exhibited weak activity compared to raw SMV with an $\mathrm{IC}_{50}$ about 25 -fold higher than that of raw SMV. Interestingly, in comparison to raw SMV, encapsulated SMV in CH-E S100 MPs had the greatest proliferation-inhibiting activity (almost double).

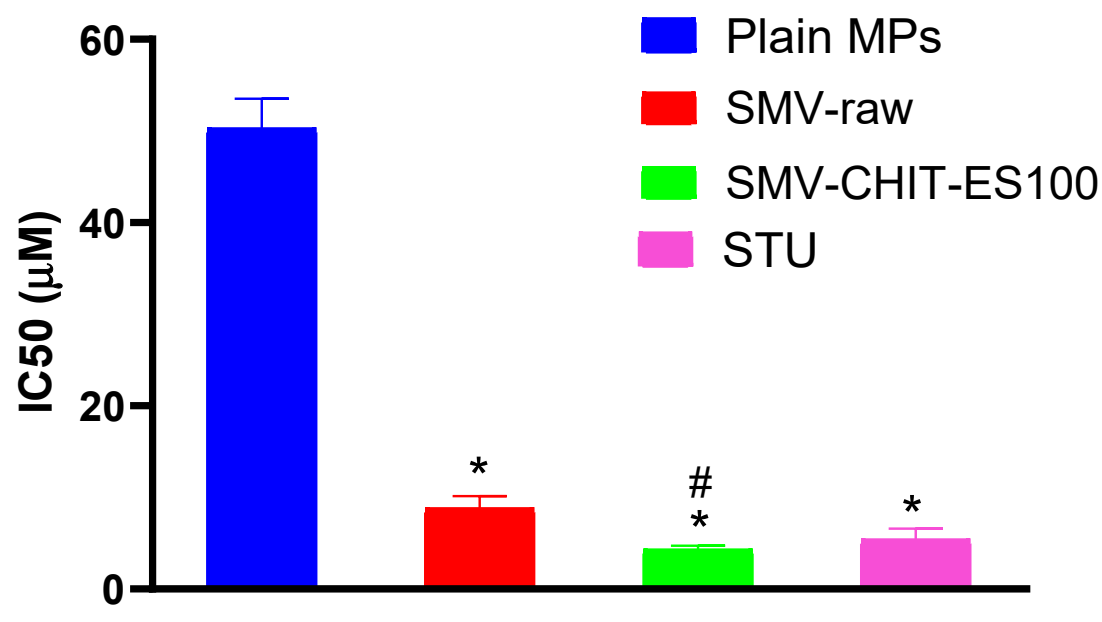

Figure 3. $\mathrm{IC}_{50}$ of the raw SMV, Plain MPs and SMV-CH-E S100 MPs in the HCT-116 cell line, as well as Staurosporine (STU). *, Significantly different, $(p<0.05)$ compared to Plain; \#, Significantly different $(p<0.05)$ compared to SMV.

\subsection{Cell Cycle Progression Analysis}

Non-treated HCT-116 cells displayed quick proliferative properties, with the G0/G1 phase giving $49.62 \pm 1.8 \%$, the S phase $36.15 \pm 2.4 \%$, the G2/M phase $14.14 \pm 1.2 \%$ and the pre-G1 phase $2.07 \pm 0.05 \%$ (Figure 4A). Incubation with Plain MPs, SMV and SMV-CHIT-ES100 MPs significantly inhibited the proliferation of the HCT-116 cells and resulted in the accumulation of cells in the G2/M and pre-G phases (Figure 4B-D). In particular, in the pre-G phase the accumulation was $19.28 \pm 0.19 \%, 16.51 \pm 0.7 \%$ and $31.49 \pm 1.02 \%$ for Plain MPs, SMV-raw and SMV-CHIT-ES100 MPs, respectively, compared with a control value of $2.07 \pm 0.02 \%$ (Figure $4 \mathrm{E}$ ). 
A

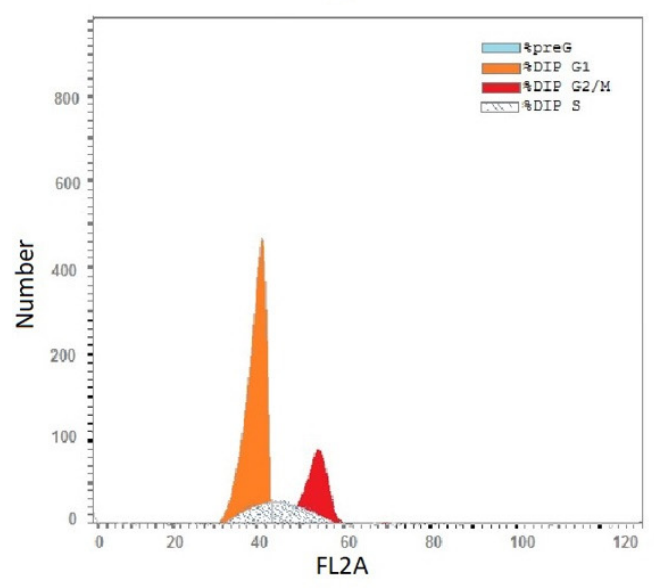

C

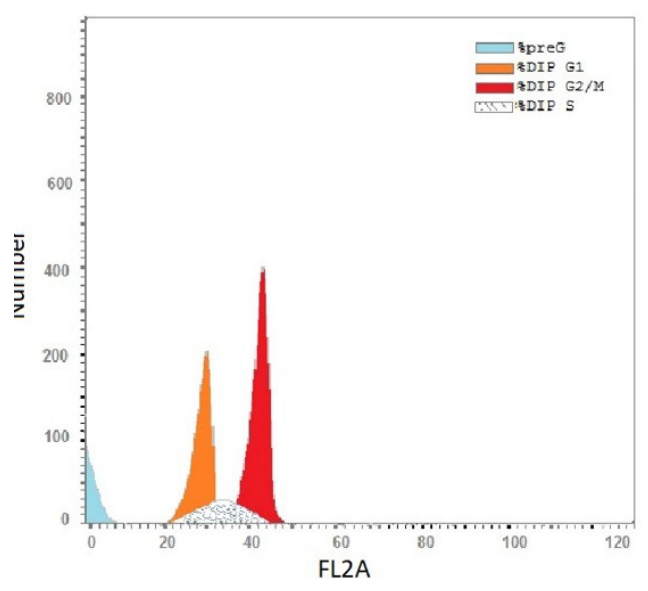

B

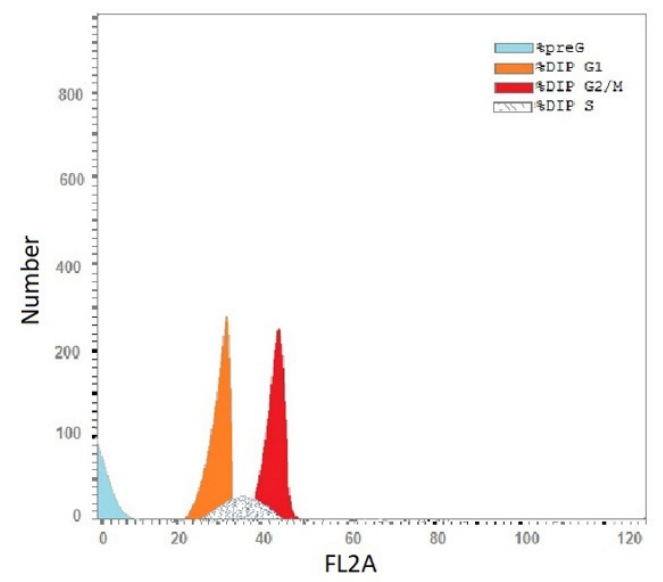

D

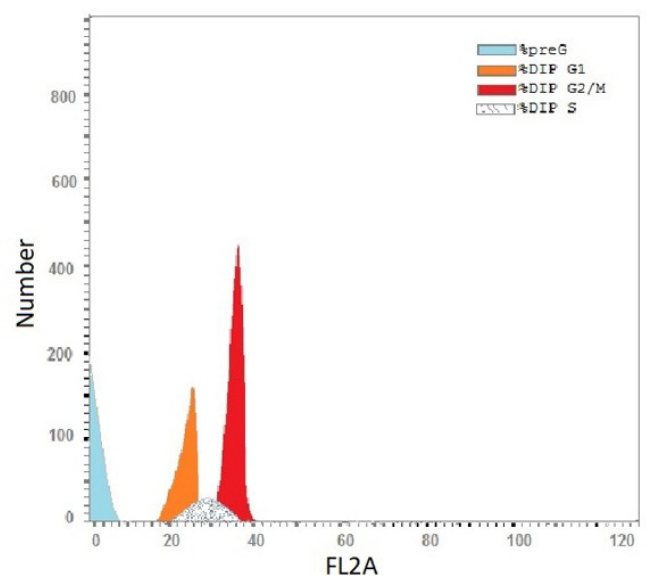

E

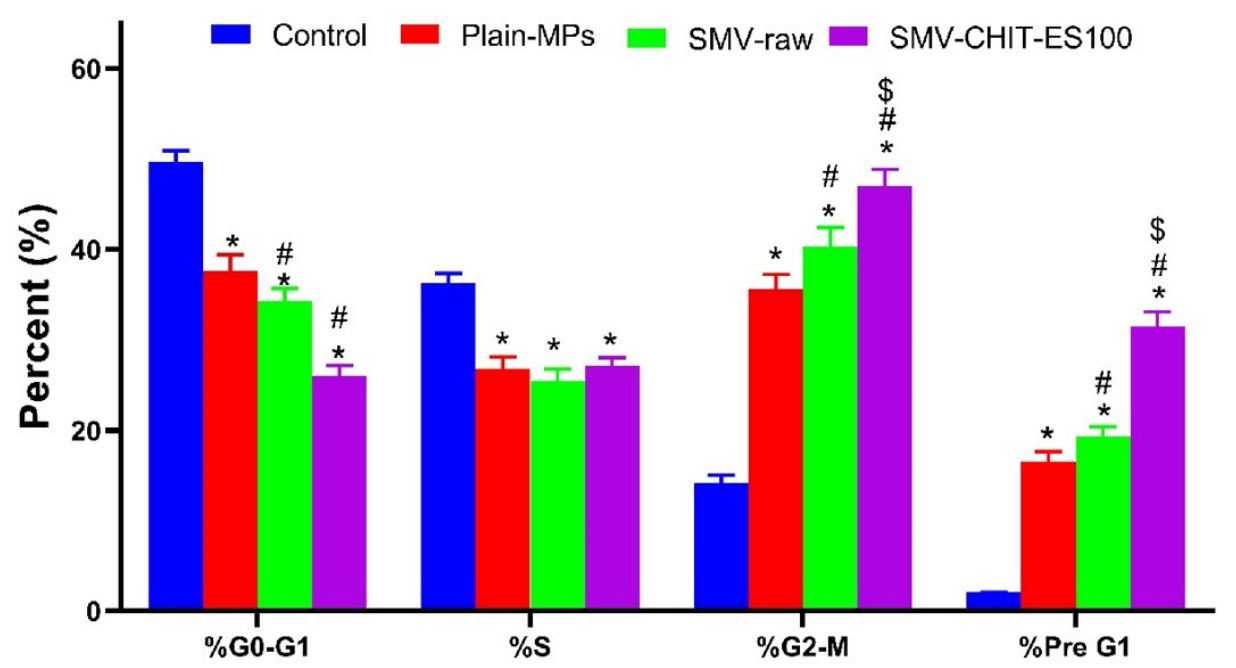

Figure 4. The impact of SMV-CHIT-ES100 MPs on HCT-116 cell cycle phases. (A) Control; (B) Plain MPs; (C) SMV-raw; (D) SMV-CHIT-ES100 MPs; (E) Graphic representations of each phase. *, Significantly different from control cells at $p<0.05$; \#, Significantly different from Plain MPs at $p<0.05 ; \$$, Significantly different from raw SMV at $p<0.05$. 


\subsection{Annexin V-FITC Apoptosis Assay and Caspase 3 Cellular Content}

The percentage of cells with a positive annexin V stain was assessed in the control, Plain MPS, SMV-raw and SMV-CHIT-ES100 MPs incubations in order to further study the observed cell apoptotic death (Figure 5A-D respectively). In comparison to other incubations, SMV-CHIT-ES100 MPs increased the early, late and total cell death (Figure 5E).
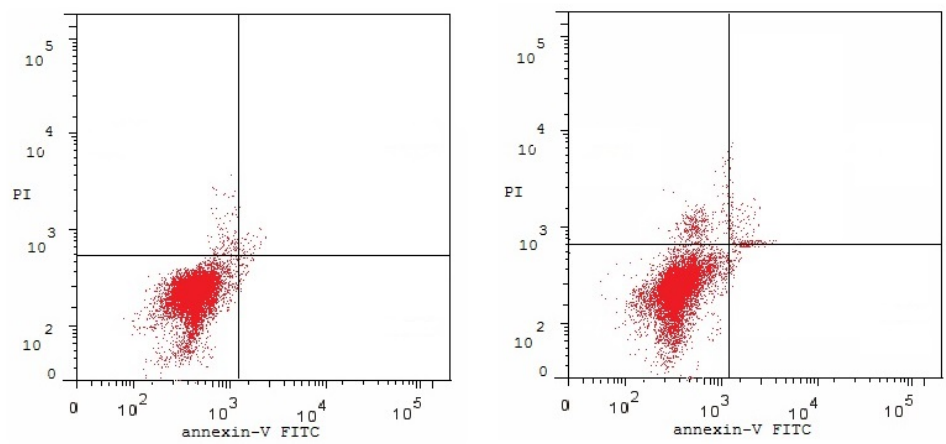

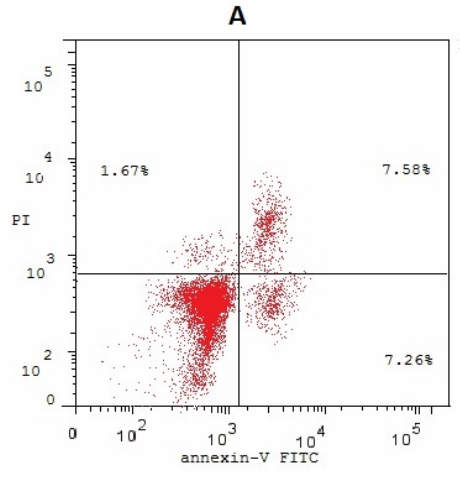

C

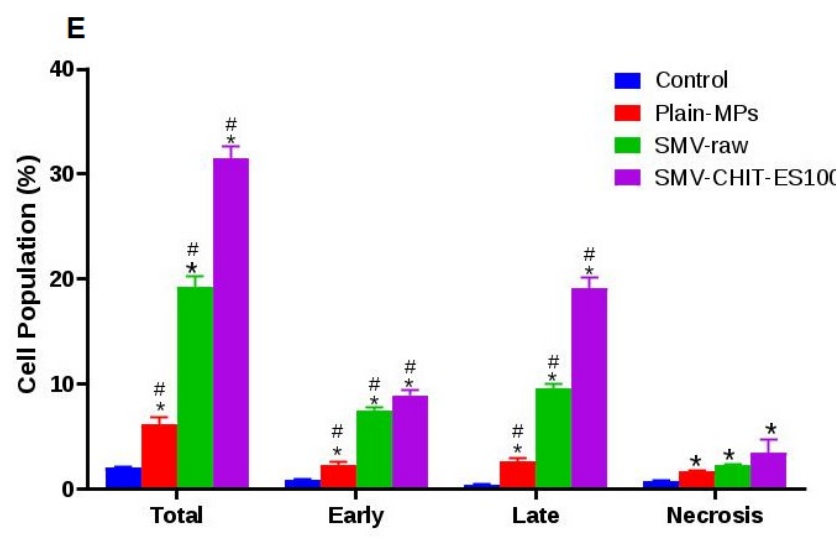

Figure 5. Impact of SMV-CHIT-ES100 MPs on the annexin V FITC positive-staining HCT-116 cells. (A) Control; (B) Plain MPs; (C) SMV-raw; (D) SMV-CHIT-ES100 MPs; (E) Graphical representations of each phase. *, Significantly different from control cells at $p<0.05$; \#, Significantly different from Plain MPs at $p<0.05 ; \$$, Significantly different from raw SMV at $p<0.05$.

The caspase 3 content also confirmed the observed apoptotic cell death induced by the SMV, SMV-CHIT-ES100 MPs. Exposure of the cells to SMV-CHIT-ES100 MPs yielded the highest content of caspase $3(548.8 \pm 13.7 \mathrm{pg} / \mathrm{mg}$ protein) when compared to a control value of $45.39 \pm 2.62 \mathrm{pg} / \mathrm{mg}$ protein and $362.6 \pm 1.96 \mathrm{pg} / \mathrm{mg}$ protein for raw SMV (Figure 6). 


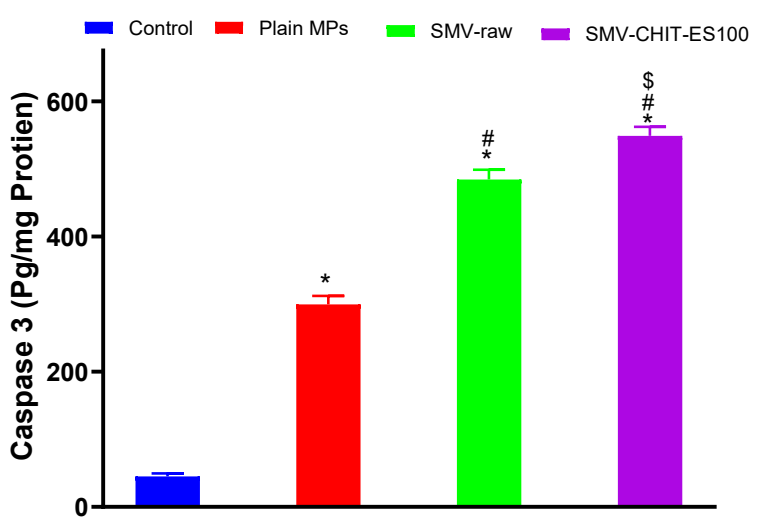

Figure 6. Impact of Plain MPs, SMV-raw, SMV-CHIT-ES100 MPs on caspase 3 enzyme concentrations in HCT-116 cells. *, Significantly different from control cells at $p<0.05$; \#, Significantly different from Plain MPs at $p<0.05 ; \$$, Significantly different from raw SMV at $p<0.05$.

\subsection{Realtime X-ray Radiography of Iohexol Formulated in CHIT-ES100 MPs in Rabbits}

The data in Figure 7 suggest that iohexol loaded in hard gelatin capsules was detected in the stomach at $15 \mathrm{~min}$ and reached the colon at $45 \mathrm{~min}$ after oral administration. However, the contrast medium was not detected at $1 \mathrm{~h}$. Thus, no further assessment of the medium in the hard gelatin capsules was performed after $1 \mathrm{~h}$ of its administration. On the other hand, iohexol-loaded CHIT-ES100 MPs was detected in the stomach at $3 \mathrm{~h}$ and $6 \mathrm{~h}$. After that, the contrast medium was obviously detected in the colon at the period 6-9 $\mathrm{h}$ after ingestion. The contrast started to disappear from $9 \mathrm{~h}$ and continued thereafter.

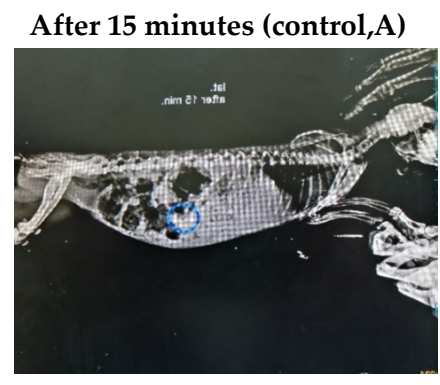

After 3 h (SMV-CHIT-ES100 MPs,D).

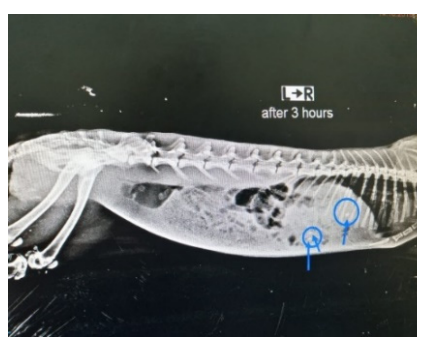

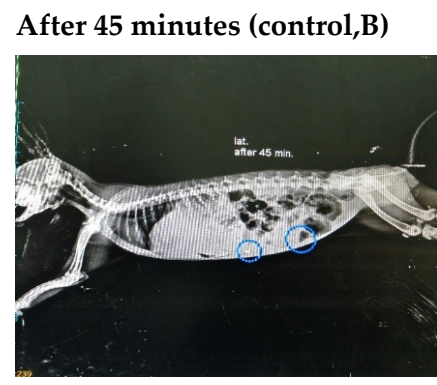

After 6 h (SMV-CHITES100 MPs,E)

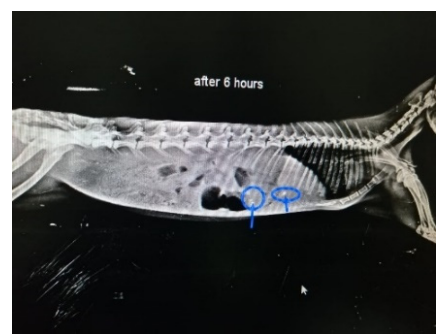

After $1 \mathrm{~h}$ (control,C)

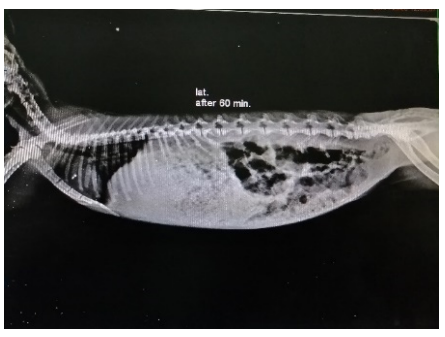

After 9 h (SMV-CHIT-E S100 MPs,F)

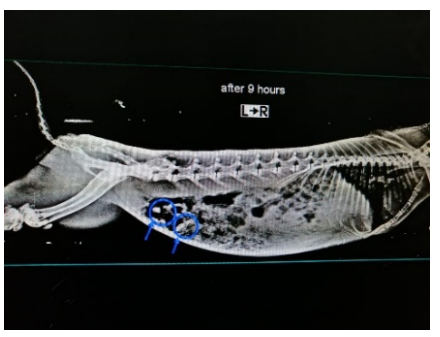

Figure 7. X-ray photographs of (control) after 15 (A), 45 (B) and $60 \mathrm{~min}$ (C) and for SMV-CH-E S100 MPs after 3 (D), 6 (E) and $9 \mathrm{~h}(\mathrm{~F})$.

\section{Discussion}

Glutaraldehyde cross-linking was developed for stable SMV-CHIT-ES100 MPs of spherical shape and size of approximately $172 \pm 28 \mu \mathrm{m}$. The drug entrapment is the result of ionic interaction and 
hydrogen bonding between $\mathrm{CH}$, glutaraldehyde and SMV, which can be explained well with the high EE percentage of SMV [12,13]. An explanation of the in vitro drug release pattern may be given as such: from 0 to $4 \mathrm{~h}$ only less than $10 \%$ of SMV was released, which is rationalized by ES100 not dissolving in acidic $\mathrm{pH}$. While SMV release started after $6 \mathrm{~h}$, as the ES100 begins to dissolve at alkaline $\mathrm{pH}$ that allows SMV-Chitosan particles to dissolve and dissolute their content. In addition, the degradation of SMV-CHIT-ES100 MPs is a hydrolytic reaction whereby glucosamine-glucosamine, glucosamine- $\mathrm{N}$-acetyl glucosamine and $\mathrm{N}$-acetyl glucosamine- $\mathrm{N}$-acetyl glucosamine links are broken, causing increased release [14-16]. Our data indicated that both SMV-raw and SMV-CHIT-ES100 possess potent antiproliferative activity and, in this regard, SMV-CHIT-ES100 showed significant potentiation of SMV cytotoxicity against HCT-116 cells. In general, statins were shown to inhibit the mevalonate pathway [9]. This causes the depletion of the intermediates in the mevalonate pathway, namely farnesyl pyrophosphate (FPP) and geranylgeranyl pyrophosphate (GGPP) [17-19]. The depletion of FPP and GGPP causes the disruption of Rho protein prenylation which may explain the cytotoxic effects [20]. In this context, our data are consistent with previous studies reporting the cytotoxicity of SMV. These include SMV cytotoxicity against U266 myeloma cells [3,11], T47D, SKBR3 and MCF-7 breast cancer cells [21-23], PC-3 prostate cells [24] and GMK green monkey kidney cells [24].

Analysis of cell cycle phases indicated that colon cancer cells challenged with SMV-raw and SMV-CHIT-ES100 were significantly accumulated in G2/M and pre-G phases, highlighting the proapoptotic activity of SMV. This result is in line with previous reports showing the capability of SMV to cause apoptosis in LipPD1 lipoma cells [25], AXT osteosarcoma cells [26] SK-N-AS neuroblastoma cells [27], PC3 and DU 145 prostate cancer cells [25], D283 and D341 medulloblastoma brain tumor cells [25-28]. The proapoptotic activity of SMV and SMV-CHIT-ES100 was further confirmed using annexin V staining technique and assessing cellular content of caspase 3 content. Our results revealed significant enhancement of early and late apoptosis as well as caspase 3 content in HCT-116 colon cancer cells. Previous work in C57/BL6 has also shown that SMV is capable of reducing the growth of tumors in the colitis-associated colon cancer (CAC) model. In addition, in order to establish a xenograft model, 53106 COLO205 cells were inoculated subcutaneously into BALB / c nu / nu mice and it was found that SMV-treated animals had smaller tumors, greater areas of necrosis, lower expression of VEGF and higher scores of apoptosis when compared to controls [29-32]. The mucoadhesive properties of Chitosan and its cationic derivatives are recognized and have been shown to enhance drug adsorption particularly at neutral $\mathrm{pH}$ [33-35]. Other hypotheses suggested was that Chitosan is a charged polysaccharide capable of adsorbing to a cancer cell. Electrostatic interactions between cancer cells and polycation polymers greatly change the permeability of cancer cells. Tumor cells have not been documented to be damaged directly by Chitosan. Such small oligosaccharides are inhibited by the activation of AMP-activated protein kinase (AMPK) and the mechanistic target of rapamycin (mTOR) [36,37]. Other work has revealed the ability of Chitosan as an immunostimulatory agent which may be used in immunomodulation-related anticancer therapy. Chitosan and its derivatives have been used as an anticancer drug carrier. It has been investigated whether anticancer agents conjugated with chitosan may have anticancer effects with a decrease in side effects and a progressive release of free drugs in cancer tissues [38]. Liposome-chitosan nanoparticles have been used to achieve a dose-dependent tumor-weight drug release inhibition device, which has shown promising results in in vivo studies [39].

Finally, the colon targeting efficiency of the prepared CHIT-ES 100 coat was evaluated by real time X-ray radiography using an iohexol contrast medium in rabbits. Compared to regular hard gelatin capsules, the prepared formula delivered its content into the colon at 6-9 $\mathrm{h}$ which is typically the time required for GIT contents to reach the colon [40,41]. These data gain support from our previous observation of SMV release which peaked at a $\mathrm{pH}$ of 7.4 in 6-9 h after formula administration. In conclusion, SMV-loaded chitosan coated with eudragit S100 formula displayed enhanced cytotoxicity and proapoptotic activity against HCT-116 colon cancer cells, as well as improved colon targeting efficiency. 


\section{Materials and Methods}

\subsection{Materials}

Eudragit $^{\circledR}$ S100 was gifted by Evonik Industries AG (Essen, Germany). SMV was a gift from SAJA pharmaceuticals (Jeddah, Saudi Arabia). 96-well plates and 12-well plates (Corning transwell ${ }^{\circledR}$ polycarbonate membrane) were obtained from Corning Co., Ltd., (Corning, NY, USA). Chitosan from shrimp shells, Dulbecco's modified Eagle medium (DMEM), PBS, and the fetal bovine plasma (FBS) and trypsin-0.02\% EDTA, were purchased from Sigma Aldrich (St. Louis, MO, USA). Cell counting Kit-8 (CCK-8) was obtained from Boster Biological Technology Co., Ltd., (Wuhan, China). Radio-Immunoprecipitation Assay (RIPA) cell lysates from Vazyme Biotech Co., Ltd., (Nanjing, China) were used. Pentobarbital sodium salt was from Merck Co., Ltd. (Darmstadt, Germany).

\subsection{SMV-CHIT-ES100 MPs Preparation}

The two-step procedure developed by Thakral et al. was used for the preparation of chitosan microparticles [42]. A $0.5 \%$ acetic acid aqueous solution was used briefly to dissolve chitosan into a solution by stirring at ambient temperature. $0.01 \mathrm{~mol} / \mathrm{L} \mathrm{NaOH}$ was used to adjust the $\mathrm{pH}$ to 5.5 . SMV was dispersed in chitosan solution and the dispersion was passed through 24-gauge needle into liquid paraffin contains $2 \%$ span 80 that was stirred at $2000 \mathrm{rpm}$ by a mechanical stirrer. After that, glutaraldehyde $(10 \mathrm{~mL}, 25 \% \mathrm{v} / \mathrm{v})$ was added to the dispersion. The addition of $5 \mathrm{~mL}$ of glutaraldehyde solution followed glutaraldehyde addition by 1 and $2 \mathrm{~h}$. After $1 \mathrm{~h}$, liquid paraffin was decanted, and the collection, washing with petroleum ether and lyophilization of SMV-chitosan microparticles were performed. For encapsulation of core SMV-chitosan microparticles with ES100, an ES100 solution $(10 \% \mathrm{w} / \mathrm{v})$ in acetone-ethanol (2:1) was used for the dispersion of the SMV-chitosan microparticles. This was followed by dropping into mechanically stirred liquid paraffin having $2 \% \mathrm{v} / \mathrm{v}$ span 80 . Stirring continued for $4 \mathrm{~h}$. Filtration, washing with petroleum ether and drying of the formed SMV-chitosan coated ES100 microparticles was then carried out.

\subsection{Characterization of SMV-CHIT-ES100 MPS}

\subsubsection{Scanning Electron Microscopy}

Double-sided adhesive tape was used to attach the samples to metal stubs to allow for examination. The tape was previously soldered to the stubs and a vacuum was used to provide a gold coating. In order to ensure the SMV-CHIT-ES100 MPs formula surface morphology, a scanning electron microscope (JEM 100-CX; JEOL, Tokyo, Japan) was employed.

\subsubsection{Encapsulation Efficiency}

High-performance liquid chromatography (HPLC)was used after dissolution of the sample in ethanol and filtration through a $0.22 \mu \mathrm{m}$ filter [43]. Equation (1) was used to calculate the encapsulation efficiency percentage (EE\%) of SMV.

$$
\mathrm{EE} \%=\frac{\text { Amount of SMV in the formula }}{\text { Amount of SMV initially added }} \times 100
$$

\subsubsection{SMV In Vitro Release from SMV-CHIT-ES100 MPs}

Coated microspheres were accurately weighed to correspond to $2 \mathrm{mg}$ of SMV and were placed in a buffer $(250 \mathrm{~mL}, \mathrm{pH} 1.2)$ and magnetically stirred at $50 \mathrm{rpm}$ for $2 \mathrm{~h}$. Centrifugation was carried out and a $0.45 \mu \mathrm{m}$ membrane filter was used to filter the supernatant for analysis of SMV content. After the $2 \mathrm{~h}$ in the buffer ( $\mathrm{pH} 1.2$ ), solution was substituted with $250 \mathrm{~mL}$ of buffer $\mathrm{pH} 4.5$ for $2 \mathrm{~h}$ and then substituted with $250 \mathrm{~mL}$ of buffer $\mathrm{pH}$ 7.4. Centrifugation, filtration and analysis of SMV content was carried out for the withdrawn samples. Triplicates of the tests were carried out. 


\subsubsection{Cell Culture}

DMEM culture medium, with glutamine and $10 \%$ fetal bovine serum was used to raise the stock culture of HCT-116 cells. The medium was replaced every 2 days. Trypsin (2.5\%)-EDTA solution (Gibco, Waltham, MA, USA) was used to detach the cells. They were then seeded into sterile 96-well plates. The cell density of each well was $30,000-50,000$. Incubation of the cells was performed at $37^{\circ} \mathrm{C}$ with $5 \% \mathrm{CO}_{2}$ content.

\subsubsection{Anti-Proliferative Activity}

The cytotoxicity of plain MPs, SMV, SMV-CHIT-ES100 MPs and staurosporine (STU, as a positive control) was determined using MTT assay kit (Sigma-Aldrich, St. Louis, MO, USA) after an incubation period of $48 \mathrm{~h}$ with different concentrations of the test compounds at logarithmic intervals. The assay was carried out according to the recommendations of the supplier with minor modifications. The assay was performed in 24-well plates using a volume of $200 \mu \mathrm{L}$ and a final MTT concentration of $100 \mu \mathrm{g} / \mathrm{mL}$ in the culture medium. After $1.5 \mathrm{~h}$, the medium containing MTT was aspirated off and replaced by the solubilization solution $(10 \%$ sodium dodecyl sulfate in $0.01 \mathrm{M} \mathrm{HCl})$. The incubation lasted for $2 \mathrm{~h}$. Then, the colored solution was transferred to 96-well plates and measured in an ELISA reader at $540 \mathrm{~nm}$.

\subsubsection{Analysis of Cell Cycle Progression}

A flowcytometer (FACSCalibur, BD Bioscience) was utilized in the determination of the cell cycle DNA distribution to, as previously described [44]. Briefly, $3 \times 105$ cells/well were used in seeding the six-well cell culture plates. SMV-CHIT-ES100 MPs equivalent to $(0.1 \mu \mathrm{M})$ SMV was applied to the cells, and equivalent concentrations of SMV and plain MPs for one day. CycleTEST ${ }^{\mathrm{TM}}$ PLUS DNA Reagent Kit (Becton Dickinson Immunocytometry Systems, San Jose, CA, USA) was employed to analyze the cell cycle. The DNA Index (DI) of the tested preparations was determined in reference to cells with a predetermined content of DNA (PBMCs). Staining was carried out using propidium iodide. Finally, CELLQUEST software (Becton Dickinson Immunocytometry Systems, San Jose, CA, USA) was used along with a DNA cytometer to assess cell distribution in the cell cycle phases.

\subsubsection{Annexin V Assay}

The assay was carried out using the Annexin V-FITC Apoptosis Detection Kit (BioVisionResearch Products, Mountain View, CA, USA). In order to identify cells in early and late apoptosis, Annexin $\mathrm{V}$ stain was used along with propidium iodide (PI). PI enters damaged and dead cells, and does not permeate cells with intact membranes. A negative PI and annexin V result suggests that the cells are viable, whereas a positive annexin $\mathrm{V}$ and negative PI results suggests early apoptosis. If a positive annexin V and PI result is obtained the cells are considered to be dead or in late apoptosis [17].

\subsubsection{Caspase-3 Enzyme Assay}

HCT-116 cells were cultured in a 96-well plate with $1.8 \times 10,000$ cells/well for $24 \mathrm{~h}$. Then, cells were exposed to SMV-CHIT-ES100 MPs containing $(0.1 \mu \mathrm{m})$ SMV or equivalent concentrations of SMV-raw and plain MPs for $24 \mathrm{~h}$. Cells were lysed by a cell extraction buffer and a $100 \mu \mathrm{L}$ sample from each incubation was used for assaying caspase-3 using a commercial kit (USCN Life Science Inc., Wuhan, Hubei, China).

4.3.9. Realtime X-ray Radiography of the Contrast Medium Iohexol Formulated in Chitosan-Coated Eudrgit in Rabbits

The handling of rabbits was approved by the Institutional Review Board for Animal Research/Studies who ensured that the care and use of animals conformed to the EU Directive 2010/63/EU on the protection of animals used for scientific purposes. The animals were kept at 
a temperature of $25{ }^{\circ} \mathrm{C}$ in a controlled environment (relative humidity $45 \%$ ) with light/day cycles. Optimum X-ray radiographic conditions were established (Supplementary file 1). The animals were kept on standard food pellets and had free access to water. Overnight fasted male New Zealand rabbits, weighing 2-2.2 kg were used. The animals were divided into two groups $(n=6)$. The first group served as a control in which each rabbit was given a single oral plain capsule containing $100 \mathrm{mg}$ of $48.5 \% \mathrm{w} / \mathrm{w}$ iohexol. Animals in the second group were administered capsules containing $100 \mathrm{mg}$ of $48.5 \% \mathrm{w} / \mathrm{w}$ iohexol in chitosan-coated eudrgit prepared as MPs. To prevent capsular destruction, the capsules were kept behind the tongue. The dose of iohexol was chosen based on a preliminary experiment. The animals were kept in rabbit restrainers. The targeting efficiency of the chitosan-coated eudrgit was determined by assessing the contrast generated by iohexol. Radiography was performed at 15, $45 \mathrm{~min}$ then after 1, 3, 6 and $9 \mathrm{~h}$, using villa X-ray medical system (Visitor-Italy).

\subsubsection{Statistical Analysis}

Data are presented as the Mean \pm SD. Statistical tests were carried out using IBM SPSS ${ }^{\circledR}$ statistics software, version 25 (SPSS Inc., Chicago, IL, USA). Analysis of Variance (ANOVA) followed by Tukey as a post hoc test was used to compare means. $p<0.05$ indicated statistical significance.

\section{Conclusions}

SMV-CHIT-ES100 MPs were successfully prepared with advantageous properties significant release at $\mathrm{pH} 7.4$ and muco-adhesion to the colonic tissues. The formulated SMV-loaded chitosan and coated with eudragit S100 displayed enhanced cytotoxicity and proapoptotic activity against HCT-116 colon cancer cells, as well as improved colon targeting efficiency.

Supplementary Materials: The following are available online at http://www.mdpi.com/1660-3397/18/4/226/s1, details of X-ray Dose determination.

Author Contributions: Conceptualization, U.A.F. and N.A.A.; methodology, S.Z.O.; software, H.Z.A.; validation, H.M.A. and M.K.; formal analysis, W.H.A. and A.I.M.; investigation, A.B.A.-N.; resources, B.G.E.; data curation, G.C. and F.C.; writing—original draft preparation, M.N.A.; writing-review and editing, M.A.B.; visualization, O.A.A.A.; supervision, N.A.A.; project administration, O.A.A.A.; funding acquisition, U.A.F. All authors have read and agreed to the published version of the manuscript.

Funding: This project was funded by the Deanship of Scientific Research (DSR) at King Abdulaziz University, Jeddah, under grant no. (RG-10-166-38). The authors, therefore, acknowledge with thanks the DSR for technical and financial support.

Conflicts of Interest: The authors declare no conflict of interest. The funders/company had no role in the design of the study; in the collection, analyses, or interpretation of data; in the writing of the manuscript, or in the decision to publish the results.

\section{References}

1. Reddy, B.S.; Reddy, B.S. Diet and Colon Cancer: Evidence from Human and Animal Model Studies. In Diet, Nutrition, and Cancer: A Critical Evaluation; CRC Press: Boca Raton, FL, USA, 2018; pp. 47-66.

2. Schabas, R.E. Colorectal cancer screening in Canada: It's time to act. Cmaj 2003, 168, 178-179. [PubMed]

3. Wolpin, B.M.; Mayer, R.J. Systemic Treatment of Colorectal Cancer. Gastroenterology 2008, 134, 1296-1310. [CrossRef]

4. Coelho, J.F.; Ferreira, P.C.; Alves, P.; Cordeiro, R.; Fonseca, A.C.; Góis, J.R.; Gil, M.H. Drug delivery systems: Advanced technologies potentially applicable in personalized treatments. EPMA J. 2010, 1, 164-209. [CrossRef]

5. Lima, I.A.; de Khalil, N.M.; Tominaga, T.T.; Lechanteur, A.; Sarmento, B.; Mainardes, R.M. Mucoadhesive chitosan-coated PLGA nanoparticles for oral delivery of ferulic acid. Artif. Cells Nanomed. Biotechnol. 2018, 46, 993-1002. [CrossRef] [PubMed]

6. Bai, J.; Zhang, Y.; Chen, L.; Yan, H.; Zhang, C.; Liu, L.; Xu, X. Synthesis and characterization of paclitaxel-imprinted microparticles for controlled release of an anticancer drug. Mater. Sci. Eng. C 2018, 92, 338-348. 
7. Isely, C.; Hendley, M.; Murphy, K.; Kader, S.; Annamalai, P.; Jabbari, E.; Gower, R.M. Development of microparticles for controlled release of resveratrol to adipose tissue and the impact of drug loading on particle morphology and drug release. Int. J. Pharm. 2019, 568, 118469. [CrossRef]

8. Samrot, A.V.; Akanksha Jahnavi, T.; Padmanaban, S.; Philip, S.A.; Burman, U.; Rabel, A.M. Chelators influenced synthesis of chitosan-carboxymethyl cellulose microparticles for controlled drug delivery. Appl. Nanosci. 2016, 6, 1219-1231. [CrossRef]

9. Aldawsari, H.M.; Elfaky, M.A.; Fahmy, U.A.; Aljaeid, B.M.; Alshareef, O.A.; El-Say, K.M. Development of a fluvastatin-loaded self-nanoemulsifying system to maximize therapeutic efficacy in human colorectal carcinoma cells. J. Drug Deliv. Sci. Technol. 2018, 46, 7-13. [CrossRef]

10. Fahmy, U.A. Augmentation of Fluvastatin Cytotoxicity Against Prostate Carcinoma PC3 Cell Line Utilizing Alpha Lipoic-Ellagic Acid Nanostructured Lipid Carrier Formula. AAPS PharmSciTech 2018, 19, 3454-3461. [CrossRef]

11. Cho, S.J.; Kim, J.S.; Kim, J.M.; Lee, J.Y.; Jung, H.C.; Song, I.S. Simvastatin induces apoptosis in human colon cancer cells and in tumor xenografts, and attenuates colitis-associated colon cancer in mice. Int. J. Cancer 2008, 123, 951-957. [CrossRef]

12. Farris, S.; Song, J.; Huang, Q. Alternative reaction mechanism for the cross-linking of gelatin with glutaraldehyde. J. Agric. Food Chem. 2010, 58, 998-1003. [CrossRef] [PubMed]

13. Rault, I.; Frei, V.; Herbage, D.; Abdul-Malak, N.; Huc, A. Evaluation of different chemical methods for cross-linking collagen gel, films and sponges. J. Mater. Sci. Mater. Med. 1996, 7, 215-221. [CrossRef]

14. Pinto, F.; de Barros, D.P.C.; Fonseca, L.P. Design of multifunctional nanostructured lipid carriers enriched with $\alpha$-tocopherol using vegetable oils. Ind. Crops Prod. 2018, 118, 149-159. [CrossRef]

15. Ghaderi, S.; Ghanbarzadeh, S.; Mohammadhassani, Z.; Hamishehkar, H. Formulation of gammaoryzanol-loaded nanoparticles for potential application in fortifying food products. Adv. Pharm. Bull. 2014, 4, 549-554.

16. Lasoń, E.; Sikora, E.; Ogonowski, J. Influence of process parameters on properties of nanostructured lipid carriers (NLC) formulation. Acta Biochim. Pol. 2013, 60, 773-777. [CrossRef] [PubMed]

17. Ali, A.; Ahmed, S. A review on chitosan and its nanocomposites in drug delivery. Int. J. Biol. Macromol. 2018, 109, 273-286. [CrossRef]

18. Prabaharan, M. Chitosan-based nanoparticles for tumor-targeted drug delivery. Int. J. Biol. Macromol. 2015, 72, 1313-1322. [CrossRef]

19. Khatik, R.; Mishra, R.; Verma, A.; Dwivedi, P.; Kumar, V.; Gupta, V.; Paliwal, S.K.; Mishra, P.R.; Dwivedi, A.K. Colon-specific delivery of curcumin by exploiting Eudragit-decorated chitosan nanoparticles in vitro and in vivo. J. Nanoparticle Res. 2013, 15, 1893. [CrossRef]

20. Fahmy, U.A.; Aljaeid, B.M. Combined strategy for suppressing breast carcinoma MCF-7 cell lines by loading simvastatin on alpha lipoic acid nanoparticles. Expert Opin. Drug Deliv. 2016, 13, 1653-1660. [CrossRef]

21. Safwat, S.; Ishak, R.A.H.; Hathout, R.M.; Mortada, N.D. Nanostructured lipid carriers loaded with simvastatin: Effect of PEG/glycerides on characterization, stability, cellular uptake efficiency and in vitro cytotoxicity. Drug Dev. Ind. Pharm. 2017, 43, 1112-1125. [CrossRef]

22. Matusewicz, L.; Podkalicka, J.; Sikorski, A.F. Immunoliposomes with Simvastatin as a Potential Therapeutic in Treatment of Breast Cancer Cells Overexpressing HER2-An In Vitro Study. Cancers 2018, 10, 418. [CrossRef]

23. Sekine, Y.; Nakayama, H.; Miyazawa, Y.; Kato, H.; Furuya, Y.; Arai, S.; Koike, H.; Matsui, H.; Shibata, Y.; Ito, K.; et al. Simvastatin in combination with meclofenamic acid inhibits the proliferation and migration of human prostate cancer PC-3 cells via an AKR1C3 mechanism. Oncol. Lett. 2018, 15, 3167-3172. [CrossRef]

24. Kässner, F.; Sauer, T.; Penke, M.; Richter, S.; Landgraf, K.; Körner, A.; Kiess, W.; Händel, N.; Garten, A. Simvastatin induces apoptosis in PTEN-haploinsufficient lipoma cells. Int. J. Mol. Med. 2018, 41, 3691-3698. [PubMed]

25. Kamel, W.A.; Sugihara, E.; Nobusue, H.; Yamaguchi-Iwai, S.; Onishi, N.; Maki, K.; Fukuchi, Y.; Matsuo, K.; Muto, A.; Saya, H.; et al. Simvastatin-induced apoptosis in osteosarcoma cells: A key role of rhoa-ampk/p38 mapk signaling in antitumor activity. Mol. Cancer Ther. 2017, 16, 182-192. [CrossRef] [PubMed]

26. Kuzyk, C.L.; Anderson, C.C.; Roede, J.R. Simvastatin Induces Delayed Apoptosis Through Disruption of Glycolysis and Mitochondrial Impairment in Neuroblastoma Cells. Clin. Transl. Sci. 2020. [CrossRef] [PubMed]

27. Sheikholeslami, K.; Ali Sher, A.; Lockman, S.; Kroft, D.; Ganjibakhsh, M.; Nejati-Koshki, K.; Shojaei, S.; Ghavami, S.; Rastegar, M. Simvastatin Induces Apoptosis in Medulloblastoma Brain Tumor Cells via Mevalonate Cascade Prenylation Substrates. Cancers 2019, 11, 994. [CrossRef] [PubMed] 
28. Lavi, R.; Zhu, X.Y.; Chade, A.R.; Lin, J.; Lerman, A.; Lerman, L.O. Simvastatin decreases endothelial progenitor cell apoptosis in the kidney of hypertensive hypercholesterolemic pigs. Arterioscler. Thromb. Vasc. Biol. 2010, 30, 976-983. [CrossRef]

29. Motawi, T.M.K.; Atta, H.M.; Sadik, N.A.H.; Azzam, M. The Therapeutic Effects of Bone Marrow-Derived Mesenchymal Stem Cells and Simvastatin in a Rat Model of Liver Fibrosis. Cell Biochem. Biophys. 2014, 68, 111-125. [CrossRef]

30. Bababeygy, S.; Polevaya, N.; Youssef, S.; Sun, A.; Xiong, A.; Prugpichailers, T.; Veeravagu, A.; Hou, L.C.; Steinman, L.; Tse, V. HMG-CoA reductase inhibition causes increased necrosis and apoptosis in an in vivo mouse glioblastoma multiforme model. Anticancer Res. 2009, 29, 4901-4908.

31. Wright, J.L.; Zhou, S.; Preobrazhenska, O.; Marshall, C.; Sin, D.D.; Laher, I.; Golbidi, S.; Churg, A.M. Statin reverses smoke-induced pulmonary hypertension and prevents emphysema but not airway remodeling. Am. J. Respir. Crit. Care Med. 2011, 183, 50-58. [CrossRef]

32. Misra, S.; Hascall, V.C.; Markwald, R.R.; Ghatak, S. Interactions between hyaluronan and its receptors (CD44, RHAMM) regulate the activities of inflammation and cancer. Front. Immunol. 2015, 6, 201. [CrossRef] [PubMed]

33. Bonferoni, M.C.; Sandri, G.; Rossi, S.; Ferrari, F.; Caramella, C. Chitosan and its salts for mucosal and transmucosal delivery. Expert Opin. Drug Deliv. 2009, 6, 923-939. [CrossRef] [PubMed]

34. Mourya, V.K.; Inamdar, N.N. Trimethyl chitosan and its applications in drug delivery. J. Mater. Sci. Mater. Med. 2009, 20, 1057-1079. [CrossRef] [PubMed]

35. Costantino, P.; Rappuoli, R.; Berti, F. The design of semi-synthetic and synthetic glycoconjugate vaccines. Expert Opin. Drug Discov. 2011, 6, 1045-1066. [CrossRef]

36. Carvalho, E.L.; Grenha, A.; Remuñán-López, C.; Alonso, M.J.; Seijo, B. Mucosal delivery of liposome-chitosan nanoparticles complexes. Methods Enzymol. 2009, 465, 289-312.

37. Wang, J.-Q.; Sui, M.; Wang, J.; Fan, W. Mechanism of Taxel-indeuced apoptosis in Breast Cancer Cells View project 81301850 View project Nanoparticles for Tumor Targeted Therapies and Their Pharmacokinetics. Curr. Drug Metab. 2010, 11, 129-141. [CrossRef]

38. Yin, D.; Chen, M.-X.; Li, B.-K.; Yin, D.-K.; Liang, J.; Li, S.-S.; Peng, D.-Y. Layer-by-layer assembly of chitosan stabilized multilayered liposomes for paclitaxel delivery Human Type II $5 \alpha$-Reductase inhibitor View project Layer-by-layer assembly of chitosan stabilized multilayered liposomes for paclitaxel delivery. Carbohydr. Polym. 2014, 111, 298-304.

39. Xiao, B.; Merlin, D. Oral colon-specific therapeutic approaches toward treatment of inflammatory bowel disease. Expert Opin. Drug Deliv. 2012, 9, 1393-1407. [CrossRef]

40. Jain, S.K.; Jain, A. Target-specific drug release to the colon. Expert Opin. Drug Deliv. 2008, 5, 483-498. [CrossRef]

41. Thakral, N.K.; Ray, A.R.; Majumdar, D.K. Eudragit S-100 entrapped chitosan microspheres of valdecoxib for colon cancer. J. Mater. Sci. Mater. Med. 2010, 21, 2691-2699. [CrossRef]

42. Fahmy, U.A. Quantification of simvastatin in mice plasma by near-infrared and chemometric analysis of spectral data. Drug Des. Devel. Ther. 2016, 10, 2507. [CrossRef] [PubMed]

43. Alhakamy, N.A.; Ahmed, O.A.; Aldawsari, H.M.; Alfaifi, M.Y.; Eid, B.G.; Abdel-Naim, A.B.; Fahmy, U.A. Encapsulation of Lovastatin in Zein Nanoparticles Exhibits Enhanced Apoptotic Activity in HepG2 Cells. Int. J. Mol. Sci. 2019, 20, 5788. [CrossRef] [PubMed]

44. Van Engeland, M.; Nieland, L.J.W.; Ramaekers, F.C.S.; Schutte, B.; Reutelingsperger, C.P.M. Annexin V-affinity assay: A review on an apoptosis detection system based on phosphatidylserine exposure. Cytometry 1998, 31, 1-9. [CrossRef]

(C) 2020 by the authors. Licensee MDPI, Basel, Switzerland. This article is an open access article distributed under the terms and conditions of the Creative Commons Attribution (CC BY) license (http://creativecommons.org/licenses/by/4.0/). 